\title{
LOS AVATARES DE LA VANGUARDIA
}

\author{
POR \\ SAUL YURKIEVICH \\ Université de Paris, Vincennes
}

REVOLUCIÓN INSTRUMENTAL, REVOLUCIÓN MENTAL, REVOLUCIÓN LITERARIA

La vanguardia instaura la ruptura de la tradición y la tradición de la ruptura. Surge íntimamente ligada a la noción de crisis generalizada, de corte radical con el pasado, de gran colapso. Aparece consubstanciada con la necesidad de cambio e impone al arte una transformación continua. Promueve una renovación profunda de las concepciones, las conductas y las realizaciones artísticas concorde con aquella que se opera en el orden tecnológico, revolución instrumental que tiene por correlato una revolución mental.

El arte de vanguardia impugna la imagen tradicional del mundo (concepción teo, geo, antropocéntrica) y el mundo de la imagen (visión perspectivista, mímesis realista, estética armónico-extensiva). Nace con el vertiginoso remodelado impuesto por la era industrial, era de las concentraciones multitudinarias en las ciudades fabriles, era de las comunicaciones rápidas, de las circulaciones internacionales, de la incorporación de las regiones más remotas al nuevo orden ahora realmente mundial. A la par de la apresurada mudanza externa, que trastoca por completo el hábitat urbano y que culmina con el cataclismo de la Primera Guerra Mundial, sobreviene una mudanza íntima, un cambio de mentalidad acompañado por una crisis raigal de valores. La realidad estable del mundo rural y artesanal, las solidaridades seculares de la comunidad local, el mundo solariego de las relaciones personalizadas son removidos, son trastornados por el estallido de los marcos familiares de vida y de referencia. El desarrollo tentacular de las grandes ciudades, la ampliación desordenada del ámbito abarcable, la forzosa entrada en el vértigo histórico provocan desajustes psicológicos y compulsan a una difícil adapta- 
ción. Las babeles voraginosas concentran heterogéneas multitudes y las obligan a incorporarse a la sociedad de masas, imponiéndoles la misma estandarización que se lleva a cabo en el orden de la producción en cadena y en gran escala. La población urbana ingresa a la vez en el reino mecánico, el de la vida unánime, y en la desmesura, en la veloz y heterogénea simultaneidad, en la mutabilidad incesante de la urbe moderna. Entra en el contexto collage. El hormiguero de hormigón, a la par que sumerge al ciudadano en el torbellino de sensaciones superpuestas, amenaza su integridad y borra su identidad; lo tensa, lo excita, lo desequilibra, lo somete a un proceso demasiado acelerado de unificación. Paisaje manufacturado, utensilios fabricados en serie, hábitat homologado, todo sustrae a los vínculos vernáculos o provoca la disyunción entre cosmopolitismo y autoctonía.

La ciudad competitiva, profana, mercantil y pragmática impone un cambio de mentalidad, propugna la religión del progreso, infunde un historicismo de avance permanente, de incesante suplantación de lo objetual y de constante modificación nocional. Desestabiliza y desplaza en una recreación permanente sin retrospección. El modelo de comportamiento avanzado, de proceder progresista, lo proveen las ciencias positivas, el modelo de producción lo dan las ciencias aplicadas: es tecnológico. Implica la constante renovación de procedimientos y de productos, que en arte se traduce a través de la permanente movilidad preceptiva y formal, por una continua controversia y una extrema diversidad estilística. Surge así, bajo la advocación del siglo mecánico, una vanguardia optimista que alaba las conquistas del mundo moderno y que asume los imperativos del programa tecnológico. Multiplica en los textos los índices de actualidad, explicita admirativamente su modernidad. Cultiva la agilidad y el simultaneísmo cinemáticos, la economía del lenguaje telegráfico, la rapidez y la condensación, la síncopa, la elipsis y la parataxis; adopta las técnicas ideográficas del afiche publicitario y de la diagramación periodística, propende al diseño abstracto; la inspira una vis geométrica. Es formalista, inventa dispositivos sofisticados, propugna la especialización y practica la experimentación. Se deja influir por el relativismo y el probabilismo de la ciencia contemporánea, que le suministra el fundamento epistemológico de sus manipulaciones aleatorias, de sus yuxtaposiciones insólitas, de su multiplicación de focos, direcciones, dimensiones. Mientras los pintores buscan incorporar el tiempo a las dimensiones espaciales, los poetas bregan por espacializar la temporalidad. Dentro de la literatura hispanoamericana, nadie representa mejor a esta vanguardia modernólatra que Vicente Huidobro, portavoz del Esprit Nouveau y de la Antitradition Futuriste de Apollinaire. 
La otra vanguardia, la pesimista, es la del turbión nerudiano de Residencia en la tierra y la del tumor de conciencia del Vallejo de Trilce; no la del pasmo, sino la del espasmo. La otra es la vanguardia atribulada, la de la angustia existencial, la del hombre que está solo y espera en medio de la multitud anónima, indiferente a su quebranto, a su orfandad. Es la vanguardia de la asunción desgarradora de la crisis, la del absurdo como universal negativo, la de la imagen desmantelada, la de la visión desintegradora. Es la vanguardia de la antiforma y la cultura adversaria, aquella que desbarajusta la textualidad establecida para dar paso a la carga del fondo impaciente, para retrotraer el lenguaje al revoltijo preformal. Es la de la belleza convulsiva, la del discurso deshilachado, la de la coherencia neurótica, la del «chorro que no sabe a cómo vamos», la del «circuito entre nuestro pobre día y la noche grande», la inmersa hasta el tuétano en el informe universo de la contingencia.

Esta vanguardia desgobierna, desacraliza y desciende; contrapone a la proyección trascendental, a la elevación sublimante y al transporte purificador, la fealdad, el sinsentido y la nonada de la existencia incompleta, oprimida por el orden indeseado, reprimida por los impedimentos empíricos. A la estilización de la poesía transfiguradora opone un registro en bruto de lo sólito, lo local, lo pedestre, de lo crudamente psicosomático, de lo incidental y lo accidental en sus mezcolanzas antitéticas, del hombre en su circunstancia, sujeto al embate desarticulador de su pugna mental y social, del hombre de la vida fraccionada, con la conciencia escindida por oposiciones inconciliables.

Imbuida de códigos negativos, esta vanguardia insurrecta, la del ser gregario en la tierra baldía, quiere desescribir lo escrito, abrirlo a las potencias desfigurantes de lo irracional. Se entrega al desquicio, al dislate, al desatino y la desproporción, desmantela la ficcionalidad mimética, revuelve la historia consecutiva, descoyunta la ilación juiciosa para permitir la inscripción de los desórdenes íntimos, el afloramiento a la superficie de la letra de los pujos entrañables. No imita las apariencias sensibles, no acata las asignaciones y designaciones de lo real legible. Agudiza el divorcio entre palabra personal y palabra pública. Da libre curso a los excesos no codificables, borra las marcas diferenciales, subvierte la subordinación de los significantes a los significados, disuelve al sujeto en el signo. El poema se vuelve palimpsesto pleno de sobresaltos, la escritura se agita y se fisura, todo perfilamiento es quebrado por los ritmos frenéticos, el decurso jadeante está impelido por una violencia sincopada, por una exasperación que no tolera detenimientos, que impide toda conclusión retórica, que somete la obra de arte a perpetuo inacabamiento. 
La estética de lo inacabado prima tanto en el orden plástico como en el literario. Lo que ocurre en la pintura es extensible a la poesía. Bordes mordidos, líneas rotas, planos quebrados, interpenetrables, los límites lineales no coinciden con las zonas de color, los objetos se liberan de su peso y levitan en un espacio que es campo de fuerzas en pugna, de energías desencadenadas. Desmenuzamiento de las superficies, el espacio escenográfico es suplantado por un espacio abierto donde todo es deformable a voluntad (la geometría euclideana es desplazada por la topología de Riemann). Los vínculos entre las partes no son concebidos en función de la distribución extensiva, según su razón de uso, sino en relación con la naturaleza íntima, con la constitución interna de los objetos, que pierden su recorte usual. La cualidad de los signos está ahora en relación con sus valores energéticos. El arte tiene que recurrir a combinaciones diferenciales para figurar la ambivalencia espacial y temporal de los fenómenos, para representar la pertenencia simultánea de un mismo signo a varios conjuntos momentáneamente constituidos. La dispersión focal, la fragmentación yuxtapuesta, los montajes diferenciales (deriva de una función por incremento de la variable) desmantelan el esquema figurativo tradicional, desarreglan la transposición lineal y global de conjuntos antes integrables, proponen una imagen del universo que no coincide con el recorte utilitario, ponen en evidencia el poder humano de crear agrupamientos muy heterogéneos regidos por otra causalidad, por una nueva concepción del tiempo y del espacio interrelacionados. A1 orden de la acción unificadora sucede el de la relatividad y la discontinuidad.

La estética de lo inacabado, de lo fragmentario y de lo discontinuo encuentra su mejor resolución formal en el collage. Inaugurado por la pintura, se hace pronto aplicable a todas las artes. El collage contrapone segmentos extraídos de contextos muy disímiles que se ensamblan en conjuntos figuradamente transitorios, casuales, sin perder su alteridad. Procede a un recorte arbitrario de fragmentos provenientes de mensajes preformados y a su redistribución en una configuración heterotópica. Cada collage establece su propia contractualidad comunicativa. Sus rupturas de articulación coexisten sin fundarse unas en otras. Objeto móvil y aleatorio, revela una prodigiosa capacidad de ligazón de conjuntos efímeros, pone en ejercicio una energía polimorfa que descentra la enunciación y libera a los signos de su inclusión convencional. Pulverizada toda relación de encuadre permanente, los fragmentos son devueltos a una combinatoria completamente abierta. Los préstamos a registros tan variados aumentan el nomadismo semántico, infunden al texto el vértigo de la deriva, lo vuelven camaleónico. El collage pone por fin en tela de juicio 
toda compatibilidad estatuida, propone un constante remodelamiento del mundo.

La obra, antes conjunción selectiva, centrípeta, se abre a la multivocidad, a la polifonía exterior, se excentra, se autoexpulsa de su vigilado dominio, se abre a la contextualidad confusa, al barullo de afuera. Se deja invadir por la palabra ajena, enajena su integridad. El collage pone en funcionamiento una retórica descompuesta, una contrarretórica; abre el texto a la irrupción desestructurante de los otros discursos, de los antagónicos; suscita una polución de acontecimientos verbales de valor indeciso que desdibuja lo literario, que lo disuelve en otros discursos o que, al generalizarlo, impide su identificación. La lengua ya no lamina, ya no alisa lo real; evidencia su disparidad, su rivalidad, su discontinuidad. El collage testimonia acerca de las condiciones de ligazón y de ruptura de toda palabra viva. El texto se desenuncia por exceso de enunciados y multiplicación de la autoría. La obra no funciona ya como totalidad autosuficiente, como una correspondencia de partes que siempre remiten al todo; de contextura ahora mixta, estrellada y estallada, se deja invadir por las otras inscripciones, por la bullanga callejera, por el fragor del extratexto, por el ruido de fondo. Se vuelve manifiestamente encrucijada intertextual, travesía de distintos vectores simbólicos, campo de contienda ideológica, integración precaria. En el collage, la heterogeneidad es la estrategia de su constitución como módulo.

$\mathrm{La}$ vanguardia funciona como toda literatura, pero extremando las tendencias. Exagera una dialéctica siempre presente en las opciones estéticas, devela la disyuntiva que preside la génesis de toda obra de arte verbal: concentrarse en lo específicamente literario o excentrarse hacia lo extraliterario. En la escritura vanguardista se da la doble vía en constante interacción: ella se deja arrebatar por el galimatías de afuera, se criba y deshilvana por efectos de la diversificación babélica, adopta la estética de la profusión entrópica, de la acumulación, del vértigo aditivo o de la voracidad implicatoria, o se repliega hacia su propia inherencia, postula como objetivo primordial su propio proceso de realización, halla en sus materiales específicos sus principios de constitución, se afirma como autosuficiente, autorreferente, autotélica. Delirio o preciosismo, pandemonio o arcano. Y por ambos rumbos la misma pérdida de la resonancia social, un mismo discurso solitario que rechaza la falsa integración, que se rebela contra el poder dominante, que renuncia a la comunicación socializada, que se determina con las fuerzas de su propia individuación, que pasa de las mitologías colectivas a las privadas, que se apoya en experiencias relegadas por el sistema utilitario al orden de la superfluo o lo recreativo para preservarlas como negación de la exis- 
tencia insatisfactoria, como alternativa utópica, como vislumbre de la sociedad deseable.

Mientras el surrealismo extrema el retiro hacia el orden preindustrial, la regresión naturalizante, y se empeña en preservar las zonas dejadas de lado por el entendimiento científico: la mentalidad mítica, la visión onírica, lo arcaico, lo esotérico, lo oracular, lo chamánico, la psicología preconsciente o lo parapsicológico, los dadaístas deciden enfrentar la situación de minusvalía provocada por el nuevo contexto urbano y por la sociedad de masas. Asumen la quiebra del orden agrario, la rotura de la cohesión social, el descrédito de la cultura humanística, la invalidez axiológica y la carencia óntica. Saben que tienen que obrar en el vacío, escribir al borde del precipicio. Procuran modificar la situación de arrinconamiento, de decepción ante el mundo inhabitable en energía transformadora. Son los primeros en aventurarse por el páramo industrial a través de experiencias de distorsión o aridez lingüísticas. Como no pueden escapar factiblemente al desbarajuste y al vaciamiento, los enfrentan mediante tácticas de choque o de diversión. Buscan liberarse de la insignificancia o del sometimiento sociales por la reversión humorística, los descalabros burlescos, la irreverencia juguetona, por los efectos de sorpresa, por el non sens, por la extrema incoherencia, por una estética de la mutabilidad capaz de emplear cualquier material, cualquier procedimiento como ariete o garrocha para sobrepasar los sentidos admisibles. Inmersos por la cultura del consumo y del desecho, inventan el arte residual (trash-art) capaz de aprovechar estéticamente la gran diversidad de desperdicios del mundo industrial. En contacto inmediato con la lengua colectiva, con la multiplicación y la simplificación de mensajes operados por los medios de la comunicación masiva, abren su escritura a lo coloquial y a lo popular urbanos, a la estereotipada metralla del lenguaje publicitario y periodístico. El lenguaje no obra ya como represa protectora, sino como una energía colectiva que se debe liberar conjuntamente con las otras fuerzas naturales y sociales. Si Pablo Neruda inaugura en la poesía hispanoamericana el descenso onirogenésico buscado por los surrealistas, la actitud dadaísta está representada por las infracciones humorísticas, por los trastocamientos irónicos, por las contaminaciones verbales de Trilce.

\section{EL TIEMPO REVOLVEDOR}

Es difícil formalizar el hervidero de manifestaciones multiformes de la primera vanguardia literaria o vanguardia propiamente dicha. Cuesta 
dar cuenta por vía analítica a través del cuerdo despliegue sucesivo de esa agitación plenaria que efervesce en el comienzo de nuestra modernidad cuando somos incorporados al programa de la sociedad industrial, cuando empezamos a participar de esa nueva experiencia de la realidad, provocada por el revolucionario acrecentamiento de la capacidad del hombre para transformar la materia, en función de una englobante instrumentación técnica de los recursos del planeta. La rápida comunicación y el activo intercambio con los rincones más remotos del globo, lo mismo que la interdependencia entre los países, sujetos a la división del trabajo y supeditados a la misma economía de mercado, nos vuelve de pronto mundiales, actuales, cosmopolitas. Aunque relegados por el nuevo orden tecnológico a la condición de proveedores de materias primas y consumidores de productos manufacturados, también experimentamos el trastocamiento de las capitales aldeanas en cabezas de Goliat, en urbes babélicas, las del tráfico y el tráfago vertiginosos, las de los contrastes simultáneos que estimulan una especial excitabilidad, las de las mezcolanzas multitudinarias, las de acelerada mudanza, las removedoras masivas, las provocadoras de las más desequilibradas concentraciones. E1 arte que representa ese cúmulo prolífico, ese revoltijo transformador, es tan activo y metamórfico como el big bang que los suscita e instiga.

Cómo reducir a esquemas regidos por la cordura crítica tan bullente atolladero constantemente excentrado por la multiplicación de dimensiones, direcciones, focos, modos, marcos de referencia, escalas; cómo regular ese veloz entrevero de probabilidades fugaces íntimamente consustanciado con las nociones de colapso, cambio, dinamismo, azar, ruptura, discontinuidad, relatividad, fragmentación. Cómo formalizar mediante la mesura exegética el arte de la explosión arrasadora, un arte que se define como subversivamente informal; cómo inteligir el arte de la visión caótica, de la extremada irracionalidad, de los mensajes entrópicos llevados al límite de la comunicación comunicable. Agente de la contracultura o cultura adversaria, la vanguardia busca mediante intervenciones contraventoras o catastróficas invalidar, más que las preceptivas vigentes, los antiguos sistemas de representación simbólica de la realidad. $\mathrm{Su}$ acción se asienta sobre todo en códigos negativos. Antiarte (underground, off off), en literatura se propone desescribir lo escrito, descodificar, desestabilizar, desautomatizar, desgramaticalizar, desestructurar, descompaginar los dispositivos textuales instaurados para sacar la escritura de sus fijaciones conceptivas, perceptivas y preceptivas para propiciar otro sistema simbólico que permita redisponer lo real restableciendo una nueva concertación entre visión y representación del mundo. Como 
sucede en el ámbito de las otras conductas técnicas, también en el campo del arte se pone de manifiesto la creciente diversificación de modos y medios que corresponde a una pluralidad tanto cognoscitiva como operativa, a la vez que todos los órdenes (tiempo/espacio, objetivo/subjetivo, natural/artificial, real/imaginario, necesidad/azar) se interfieren e interpenetran en multívocas mixturas.

Este arte de la tensión disonante, de la transversalidad o la alienación negativas muestra la dificultad de instalación mental en la modernidad, revela que el pasaje de la vieja a la nueva visión no se ha consumado todavía; quizá nunca llegue a consumarse. Incluso en los heraldos del siglo mecánico, en los portavoces de la modernolatría, como Vicente Huidobro, se va a hacer ver ese conflicto permanente de los vanguardistas entre la voluntad de inscribirse como contemporáneos cabales, de entrar y hacer pleno pie en el tiempo histórico, en esa veloz sustitución, en la cambiante momentaneidad y en el consumo vertiginoso de la sociedad industrial que suplanta constantemente sus productos, incluso los culturales, y en oposición irreconciliable la añoranza paradigmática de permanencia y de trascendencia. Desde el comienzo aparece y persiste el antagonismo conflictual entre un presente precario impulsado coercitivamente hacia un futuro incierto y la nostalgia de la presencia constante y total, de la completud, de lo axial, de lo numinoso; conflicto entre un hábitat manufacturado, unificado por la estandarización a escala mundial y el deseo de regresión al orden protector, al orbe maternal, al mundo mítico; conflicto entre la movilidad alucinatoria de la era de las comunicaciones y el asentamiento reparador de la autoctonía, de lo solariego y lo natal; auspicio y rechazo de la máquina; aceptación de la contingencia y ansia de perpetuación; objetivismo formalista y tecnocrático y unas ganas irreprimibles de explayar el deseo, de reingresar al dominio festivo del juego y de la sensualidad, reinstalarse en la matriz reparadora, aparecer como sujeto carnal que consigna directamente su subjetividad; descendimiento profanador de las excelsitudes y creencia en el poder catártico, aurático del arte; desublimación realista y sublimidad mística.

\section{LA TRIPLE VECTORIALIDAD DE LA VANGUARDIA}

Creo, no obstante tamaña multiplicidad enmarañada, entrever tres dominantes, tres directrices que permiten una distribución ordenadora de las manifestaciones de la modernidad, como si las trazas o marcas 
que la inscriben literariamente se dejasen conectar y articular a lo largo de estos ejes:

a) Una directriz realista/historicista, ligada a la noción de una acelerada y compulsiva actualidad sujeta a transformaciones radicales y en ruptura revolucionaria con el pasado; esta directriz promueve el señalamiento de la contemporaneidad innovadora en todas las instancias textuales e impulsa a inventar los medios de representación literaria aptos para figurar una nueva visión del mundo.

b) Una directriz formalista, liberadora de las restricciones de lo real empírico, propicia la autonomía del signo estético con respecto a todo referente exterior y desarrolla todas las potencialidades inherentes a lo literario, remitiéndolo al campo de su propia pertinencia.

c) Una directriz subjetivista, que bucea en las profundidades de la conciencia, que abre el texto a los aflujos psicosomáticos del inconsciente, que desmantela la textualidad estatuida para marcar los destiempos y desespacios, las intensidades y densidades rebeldes del fondo entrañable.

(E1 sufijo ista señala sutilmente el carácter de ideologemas de estas tendencias; da la idea de un conocimiento reflejo, de una mediación cultural, de los modos o modas que condicionan las conductas técnicas y cognoscitivas de una época en el seno de cierta sociedad.)

Esta triple vectorialidad se aplica tanto a la vertiente renovadora del modernismo como a su prolongación en la vanguardia; ella permite reforzar esa conexión causal entre el trío mayor de poetas modernistas -Rubén Darío, Leopoldo Lugones, Julio Herrera y Reissig - y sus equivalentes vanguardistas -Vicente Huidobro, César Vallejo, Pablo Neruda- que analizo en mi Celebración del modernismo (Barcelona: Tusquets, 1976). Allí intento demostrar que los postulados y prácticas fundamentales de la vanguardia son previamente preconizados y ejercitadas por los modernistas. Quizá fuera mejor englobar ambos movimientos, según lo concibe la crítica anglosajona, en un mismo complejo: la modernidad.

\section{a) Directriz realista/historicista}

La vanguardia concibe la modernidad como culto a la novedad, como afán de participar en el progreso y la expansión provocados por la revolución industrial, como empeño en manifestar el contacto con la historia inmediata con la microhistoria personal y la macrohistoria colectiva, unánime, como voluntad de gestar una literatura abierta al mundo, capaz 
de registrar la cambiante realidad en toda su extensión y en todos sus niveles, que tenga el temple, el ritmo, el nervio de un presente en rápida transformación. E1 Esprit Nouveau de Apollinaire inspira la poética del creacionismo de Huidobro y de su secuela hispanoamericana (ultraísmo, estridentismo, martinfierrismo, nadaísmo, etc.). El culto a la novedad impone al movimiento vanguardista un curso cambiante que se caracteriza por la proliferación de episódicas tendencias. Todas ellas manifiestan su fervor por un presente prospectivo, radicalmente divorciado del pasado próximo y remoto, presente compulsado hacia una futuridad en perpetuo adelanto. Las prédicas vanguardistas preconizan un antipasatismo reacio a cualquier restauración, un antiacademismo opuesto a todo renacimiento. En sus posiciones extremas, la vanguardia se presenta como instauración a partir de cero, como inauguración ex nihilo nacida de la ruptura de todos los continuos.

$\mathrm{Su}$ historicismo se funda en la conciencia de crisis, conciencia de corte empírico y epistémico que modifica el fundamento de las antiguas conductas técnicas y cognoscitivas en íntima correlación.

La vanguardia opera según una doble estrategia, la una futurista y la otra agonista. La una, afirmativa, exalta los logros del siglo mecánico, los avances en la era de las comunicaciones, las excitaciones de la urbe tecnificada, multitudinaria y babélica, el vértigo y la pujanza de lo moderno, de una actualidad mundialmente acompasada que ha roto los confinamientos regionales e idiomáticos para imponerse por doquier. La vanguardia es un fenómeno de las capitales relacionadas con el intercambio internacional. La modernolatría es una devoción ciudadana. La vanguardia aparece como índice de actualidad generado por los centros metropolitanos en su proceso de modernización; refleja el anhelo de concertar el arte local con el internacional.

La otra estrategia está presidida por una visión apocalíptica que pretende instaurar la tabla rasa, por el rechazo contundente de todo modelo tradicional, de las concepciones y formalizaciones vigentes. Se expresa a través de los códigos negativos que le imprimen ese carácter subversive de contracultura, cultura adversaria, antiarte, antiforma (secuela del dadaísmo y del surrealismo), que va a constituir una de las bases principales de su estética. Afecta a la noción de activismo, de militancia, que pone el acento en los valores voluntaristas y energéticos; la acción de la vanguardia es en gran parte labor de zapa. Inmersa en el flujo temporal para intervenir en ese dinamismo que acelera y ahonda las mutaciones, la vanguardia se impone el papel de agente desestabilizador y desestructurador de los dispositivos instituidos, quiere intervenir como fermento de una revolución en vías de generalizarse. Concibe al artista como héroe 
negativo que se sacrifica en aras del porvenir. La rebeldía y la intransigencia son inherentes a sus adeptos. Por la negación, operando mediante el sistema menos -infracción de la regla y/o sustracción de elementos definidores dentro del marco específico a cada género o forma artísticos - se proponen abolir las normativas convencionales y renovar, por la afirmación futurista y proyectiva, o por la negativa vitalista, catastrófica, la cultura de un pasado exanguie.

La modernolatría futurista y el vitalismo primitivista generan ambos una vanguardia expansiva, exultante. Imbuidos del culto al cambio que la aceleración tecnológica provoca, anexados a la cultura del consumo que suplanta constantemente sus productos, prosélitos del progreso, metropolitanos e internacionalistas, los modernólatras diseminan en sus textos ostentosos índices de actualidad. En su vislumbre y en su instrumentación del texto tratan de entablar correspondencias con la racionalidad tecnológica. Extienden a las prácticas estéticas la noción científica de experimentación. Instauran la era de los manifiestos, muestran una franca propensión programática, cultivan la disquisición teórica, la conciencia analítica, gustan de las formulaciones axiomáticas y en su deontología literaria tratan de aproximarse al empirismo y al objetivismo de los discursos científicos. A su vez, el vitalismo vigorizador postula la invalidez de la cultura letrada, reacciona contra el exceso inhibidor de la acumulación sapiente y se propone descalabrar el orden represivo a través de la barbarie liberadora, de una regresión genética que permita recuperar los poderes primigenios, la naturalidad perdida.

A la vanguardia exultante, que se prolongará a través de variantes tecnocráticas y formalistas como la del movimiento concreto, sucede una segunda época (¿cómo fecharla?, la cronología es móvil, escurridiza) en que los desajustes, las disritmias, las disrupciones se interiorizan intensificándose, en que la exaltación optimista frente a la sociedad industrial, a la cual nunca tuvimos completo acceso, se vuelve disfórica desolación, reificación, angustioso vacío, quebranto existencial con la consiguiente carencia ontológica. Trilce, Residencia en la tierra y Altazor son a la vez configuraciones poéticas de experiencias abismales y reflejos de la marginación del escritor latinoamericano en sociedades o demasiado arcaicas o de un capitalismo grosero en permanente crisis. Figuran una existencia despeñada al abismo de la nada, la de un ser en soledad cada vez más absoluta e incompartible, sujeto a una doble carencia que lo condiciona negativamente: la imposibilidad de hallar un principio de conexión, de razón suficiente y la irreversibilidad de un tiempo signado por la merma. Las probabilidades de dotar a su vivir de un sentido positivo le están vedadas: un trabajo que le permita mancomunarse productivamente con 
la comunidad o una adecuada inserción en la historia colectiva, en la historia con perspectiva de futuro reparador; carece de la posibilidad de trascendencia, de ese sentido teleológico capaz de infundir significación al presente discontinuo; carece de una dirección que pueda transformar su temporalidad en valor histórico, suprapersonal, que pueda convertir al ser individual en comunitario.

La escritura solitaria que rechaza la falsa integración social propuesta por el régimen opresivo y unificador se entrega a su propia inmanencia, acentuando, por el ejercicio de la arbitrariedad, el desatino y la desmesura, el divorcio entre palabra poética y discursos socializados. Incorpora esa tensión disonante a su propia textura y se vuelve sismógrafo de intensidades contrastantes y de choques traumáticos.

E1 registro de la actualidad aparece ostentosamente en la superficie del texto, literalmente explicitado, o se introvierte modificando el sistema de representación para proponer otra figuración y, por ende, otra aprehensión del mundo. Hay una contemporaneidad explícita que consigna la realidad moderna mediante la mención de utilería tecnológica y de adelantos urbanos, que propone una literatura ciudadana, cosmopolita, de viajeros y poliglotos, transgeográfica y translinguística, y una contemporaneidad implícita que inventa nuevos procedimientos textuales para simbolizar la vertiginosa y heterogénea multiplicidad de lo real: visión multifocal, pluralidad polifónica de instancias discursivas, montaje cinemático, sistema collage, dislocamiento de la imagen, avecinamientos antagónicos, estética de lo discontinuo y fragmentario, revolución tipográfica, recursos de velocidad, simultaneidad, ubicuidad, etc.

E1 deseo de inscribir lo real actúa como impulsor de innovación, porque la realidad es un cúmulo móvil que exige una constante adecuación de la visión, de los módulos de percepción y de los instrumentos de transcripción. La vanguardia se encarga periódicamente de restablecer el vínculo entre concepción y representación del mundo entre la actualidad cognoscitiva y la representación artística.

\section{b) Directriz formalista}

A la par que se empeñan en inscribirse como contemporáneos del siglo mecánico, los vanguardistas acrecientan la autonomía poética. Desarrollando las potencialidades específicas al arte verbal y poniendo en práctica todas las libertades textuales — de asociación, de dirección, de extensión, de disposición, de referencia- bregan por crear entidades estéticas autosuficientes, autorreferentes, autotélicas. Abolidas las restric- 
ciones empíricas, retóricas e imaginativas, se proponen dotar al poema de una forma y un sentido propios no restringidos por subordinaciones externas.

Semejante trastocamiento prosódico, tamaña transformación del lenguaje, tan enorme ampliación de lo decible y, por ende, de lo concebible provocan no sólo un corte radical en el plano estético, también un corte de orden mental, epistémico: prefiguran otra conciencia posible $y$, en última instancia, otra factualidad presumible, proponen otros modos de percibir, de idear y de representar el mundo. Este libre arbitrio es una conquista progresiva que llega a explayarse plenamente en Altazor. Allí se procede por progresión metafórica a desmantelar en todas sus instancias la lengua sujeta al orden objetivo y a la razón de uso para que la palabra recobre la plenitud de su potencia.

La sensibilidad impresionista acentuada por el modernismo promueve un ablandamiento, una fluencia, una volatilidad que vuelve vacilantes los contornos y difusos los cuerpos. Todo fluctúa, todo vibra, todo emite signos en busca de sutiles acordes. El mundo se vuelve una inmensa cámara de llamados, de ecos, de resonancias: mundo en expansión, mundo penetrable. Eliminada toda separación, la imaginación circula sin restricciones para establecer correspondencias desapercibidas, inusitadas. La sucesión y la distinción quedan invalidadas por un simultaneísmo sensual que se deleita en el apunte de estímulos evanescentes donde lo indeciso colinda con lo indecible.

Esta visión móvil, lábil, esta nebulosa fusión de fondo y forma, exenta de lo neto y de lo nítido, esta acuidad que se desapega de los sólidos estáticos y perfilados, esta ensoñación que se desobjetiva para flotar o volar volublemente conduce al abandono de lo literal en aras de lo figurado, al enrarecimiento enriquecedor, al reino de las sinestesias que musicalizan lo visual y visualizan lo auditivo, al relajamiento de la columna versal, sin isometría ni principios fijos de organización numérica, a la descomposición del cuadro en haces de sensaciones sugeridoras, en vibraciones sentimentales, en pulsiones cantarinas. La visión impresionista impulsa a sobrepasar la imaginación reproductora y la inteligencia discursiva; libera las energías reprimidas y propende a una poeticidad que se complace en el despliegue de su propia inherencia.

En contraposición al absurdo negativo de la vanguardia pesimista que convulsa y angustiosamente dice el sinsentido de la existencia y la sinrazón del mundo, en contraste con el absurdo deprimente que agrava y desagrega, con el desintegrador que disocia mente y mundo y que desgarra la conciencia, la vanguardia optimista, desembarazada de las vedas realistas, goza con el ejercicio del absurdo positivo, con el poder 
demiúrgico de anular toda distinción separadora, de provocar en el poema 1a convergencia de lo más distinto con lo más distante, de restablecer el vínculo deseado del figurador con sus figuraciones, de devolverlo todo a la unidad original.

La metáfora radical es el principal agente de la imaginación sin ataduras, el recurso privilegiado para dotar al texto de la máxima autonomía. Operador imaginante, suscita una transgresión categorial creadora de sentido inédito. Con sus desconcertantes encrucijadas, sus insólitos choques y explosiones expansivas, anula el determinismo empírico y el contrasentido lógico. Experiencia visionaria, al extremarse, deshace el mundo literal para sustituirlo por otro regido por la causalidad hilozoísta de lo metafórico. Se abre al despliegue mítico, formula lo informulable, postula entidades e identidades desconocidas: inaugura otros mundos, otras existencias posibles. Generalizada, la proliferación metafórica permite recuperar la energía originaria de la imagen, reinstala el dinamismo fundamental de la vida psíquica, la polución del comienzo, prelógica, el gran semantismo primordial que es la matriz procreadora de nuevas atribuciones significativas, de futuras pertinencias.

Rota la identificación romántica entre palabra y vida que impone al poeta decir naturalmente lo vivido, autoexpresarse espontáneamente, el poema se vuelve una construcción independiente, exenta de toda función extratextual, que instaura sus configuraciones y sus relaciones específicas, su propio universo lingüístico. Los significantes se insubordinan contra la sujeción a los significados. Desacatan la norma de economía, atenuación y transparencia que les impone el lenguaje utilitario. Dotados de extraordinario relieve sensible, invierten la relación de significación para volverse objeto del decir. El espacio y el sonido intervienen activamente en el sentido, son los conductores privilegiados de la información estética.

La vanguardia desmantela el discurso instaurado, lo convierte en un transcurso de desarrollo imprevisible que conecta por relaciones aleatorias los componentes más disímiles; vuelve el poeta excéntrico, polimorfo, politonal, polifónico, plurívoco. El texto multiplica sus convocaciones arbitrarias que desbaratan la previsibilidad y proyectan al lector fuera de las orientaciones usuales. Los marcos y las escalas de referencia se diversifican, los materiales congregados tienden al máximo de heterogeneidad. El texto se convierte en una estructura abierta, establece conexiones multivalentes, una indeterminación que multiplica la significancia y torna plural la lectura. El poema acrecienta su poder inventivo, su incitación fermentadora, su embate provocador: requiere, más que un receptor, un operador casi tan activo como el productor. 
E1 poema implicará una intervención transformadora en todas sus instancias, o sea, el máximo de tecnicidad manifiesta. Es una realización irrealizante en tanto comporta el mayor apartamiento de la comunicación habitual y de la representación considerada como natural. Se presenta como performance instrumental, como fabricación (incluso en el plano léxico), como composición (en el sentido musical), como función (en el sentido teatral), como experta manipulación.

Muestra de alarde instrumental e icónico, el poema se constituye como objeto suntuario, superfluo en relación con los valores de uso. Se convierte en un puro dispositivo placentero: se desrealiza para procurar al deseo su realización imaginaria. Artificio seductor, absuelve de las censuras realistas, del sentido común y del sentido práctico. Por su carácter de objeto lúdico, implica estado de excepción, interregno festivo. Intermediario onírico, posibilita una conducta emancipada. Negación del orden imperante, desconocimiento de todo orden represivo, se desconecta por completo de lo circunstancial y circundante para preservar una libertad que sólo puede darse en la dimensión estética.

\section{c) Directriz subjetivista}

Ya con los modernistas aparece en la escena textual la noción y los módulos de representación de la subjetividad tal cual la concebimos y la figuramos nosotros. El texto registra las perturbaciones de la conciencia, se deja cautivar por lo psicótico, explaya los estados mórbidos, las angustias desorganizadoras, el dislocamiento provocado por una espontaneidad descontrolada, el desvarío fantasmal, las alteraciones de los lazos objetuaies, el irreprimible autismo que lo retrotrae y lo avasalla al cohabitante insondable: el inconsciente. El texto se desmide, se convulsiona, se desquicia para decir las acometidas desatinadas del yo recóndito, las insumisas emergencias del fondo entrañable.

Afluyen al texto las fuerzas oscuras, las del fondo imperioso y confuso que pugnan por romper las represas de la conciencia emitiendo señales disparatadas, erráticas, una turbamulta de significantes refractarios al significado y que el lenguaje, agente del orden censorio, no puede fijar, no puede alinear, no puede formular. Ya desde Cantos de vida y esperanza, el sujeto constituido a través de una interacción reglada entre cuerpo, psique, lengua, naturaleza y sociedad no consigue o no quiere contener el estallido de una subjetividad que desborda el discernimiento y sobrepasa los límites ideológicos de la racionalidad, que perturba la conducción linguística porque no se deja asignar, no se deja distribuir 
en los sintagmas lineales, no se deja representar. Pujos psicosomáticos dispares impulsan en múltiples direcciones, compelen a desgarrar la textura, la textualidad del continuo consciente, a desbarajustar las posiciones y disposiciones del entendimiento discursivo. La irrupción discordante de ese colmo de heterogeneidad, de alteridad inasible, descoyunta la comunicación sensata, subvierte la conducta sociable e impone un descenso por debajo del orden simbólico hacia la base preverbal, hacia la intimidad donde se engendra el sujeto y se genera la significancia. La pujanza de ese exceso no codificable, centrífugo, entrópico, repulsa las significaciones estatuidas, provoca una inadecuación de los signos que descoloca y desperdiga al sujeto unitario de la lengua lineal, que remueve, atraviesa y desmembra el sistema textual.

A partir de Darío, el sujeto palpitante, opaco, del revoltijo corporal, el sujeto carnal, se enfrentará con el impasible, transparente, abstracto sujeto gramatical para movilizarlo, afantasmarlo, diversificarlo. E1 poema, de Darío a Vallejo, reflotará en lugar del sujeto constituido, un su, jeto en proceso, representado en el removimiento que lo engendra o lo disuelve, no un sujeto presupuesto (puntual) en conexión con una realidad preconcebida, sino un sujeto genético (impuntual) que promueve la figuración de relaciones inusitadas entre el consciente, el inconsciente, los objetos naturales y los aparatos sociales. La subjetividad rebelde, abatiendo sus bloqueos, se inscribirá como transversalidad negativa que descompone y recompone del dispositivo poético para manifestar su capacidad de transmutación y de conmutación: ruptura, labilidad, movilidad, ubicuidad, simultaneidad. Desarticulará la organización del texto basada en ese consenso naturalizado que prejuzga que el lenguaje debe enunciar la afectación corriente de sujetos y de objetos, la desmantelará incluso a riesgo de amenazar el funcionamiento social del lenguaje por exceso de significantes erráticos. La descodificará para reintroducirle la pluralidad pulsional, la materia impaciente, la carga corpórea de las heterogeneidades. El poema provocará el desbarajuste del discurso normativo para hacer estallar el sujeto convencional, para transgredir sus represiones, contravenir sus censuras, abolir sus límites nocionales. El proceso, reactivado por la «Psicologación morbo-panteísta» de Herrera y Reissig, reventará con la revulsiva revuelta de Vallejo. 